\title{
INFLUENCE OF PARTICIPATION IN DECISION MAKING ON JOB SATISFACTION, GROUP LEARNING, AND GROUP COMMITMENT: EMPIRICAL STUDY OF PUBLIC SECTOR UNDERTAKINGS IN INDIA
}

\author{
Shilpi Saha* and S. Pavan Kumar \\ School of Management, National Institute of Technology Karnataka, Surathkal, India \\ *Corresponding author:sh.shlp12@gmail.com
}

Published online: 30 June 2017

To cite this article: Saha, S. and Kumar, S.P. (2017). Influence of participation in decision making on job satisfaction, group learning, and group commitment: Empirical study of public sector undertakings in India. Asian Academy of Management Journal, 22(1), 79-101. https://doi.org/10.21315/aamj2017.22.1.4

To link to this article: https://doi.org/10.21315/aamj2017.22.1.4

\begin{abstract}
This study assesses the impact of participation in decision making on job satisfaction, group commitment, and group learning. Data were collected from 397 managerial employees working in public sector undertakings across India. Structural equation modeling as a statistical technique and WarpPLS as a statistical tool was used to verify the proposed relationships. The findings of the study suggest that participation in decision making had a positive and significant relationship with job satisfaction. Further, participation in decision making had significant impact on group learning, but had no impact on group commitment. Job satisfaction had a positive and significant impact on group commitment. Group learning was positively and significantly related to job satisfaction and group commitment. The results suggest that employee participation in decision making process is highly desirable as it elevates employee identification with their respective organisation. The findings of the study are relevant to the people holding key managerial positions in public sector undertakings and they are discussed in detail.
\end{abstract}

Keywords: participation in decision making, job satisfaction, group commitment, group learning, employees, public sector undertakings

(C) Asian Academy of Management and Penerbit Universiti Sains Malaysia, 2017. This work is licensed under the terms of the Creative Commons Attribution (CC BY) (http://creativecommons. org/licenses/by/4.0/). 


\section{INTRODUCTION}

In the present scenario of high competitiveness, organisations need to have a human resource pool generating high performance that cannot be substituted by its rivals (Barney, 1991). A lot of emphasis is given on performance and result-oriented services due to which participative management is considered as very essential for satisfaction of employees (Kim, 2002). Participation allows individuals to share influence among themselves who are not hierarchially equal, and participative management practices help to maintain a balance on the involvement of managers as well as the subordinates in the daily tasks and activities related to the job (Wagner, 1994). It is believed that participation makes an influence on work practices, recognition, and rewards, and these correlate with job satisfaction and organisational commitment (Appelbaum, Louis, Makarenko, \& Saluja, 2013). The highest levels of satisfaction in the work environment are likely to occur when there is high level of involvement by planning processes, generating alternatives, formulating policies, and evaluating results.

A work group is a collection of employees who work together to complete organisational goals (Kukenberger, Mathieu, \& Ruddy, 2015). Individual knowledge within a work group is necessary as it is the extent to which a work group member would perceive that his or her work specific knowledge and skills have improved as a result of working with the group. This process is considered as group learning. It is expected to be influenced by relationships between the employee and his coemployees. A positive work environment that is free of dysfunctional conflicts and has good amount of trust would help in learning within work groups. It is stated that satisfaction is positively related to group commitment (Bishop \& Scott, 2000). Both group learning and group commitment have been recognised as the main ingredients of a work group (Mathieu \& Gilson, 2012; Kukenberger et al., 2015). There is support from past research that employees learn and work as a function of getting attached to their respective work groups (Tannenbaum, Beard, McNall, $\&$ Salas, 2010).

Affective form of commitment has a strong relationship with group level outcomes and citizenship behaviours because individuals impart greater effort when they get motivated by high levels of attachment, identification, and internalisation (Giri \& Kumar, 2013). Employees exhibit meaningfully distinct levels of affective commitment towards their organisation as well as their work group (Johnson \& Yang, 2010). Hence, the present study has focused on individual's affective commitment towards their work group. Affective group commitment has been labelled as simply group commitment in this study following the convention in 
past research (Cohen, 2003). Indians have the essence of 'collectivism' or collective culture (Hofstede, 1980). Hence, they prefer to discuss and work together.

We have selected Central Public Sector Enterprises (CPSEs), also known as public sector undertakings, as our empirical setting. The reasons for selecting public sector undertakings as empirical setting are many considering personal and business fronts. Firstly, they are renowned to be people-centric and dynamic (Gupta \& Pannu, 2013). Secondly, these organisations continue to attract millions of job seekers mainly because of job security and stability (Ahmad, 2013). Thirdly, these organisations are growing in importance, nationally and internationally. According to SCOPE (2016) in India, "all public sector undertakings collectively accounted for 23.2 percent of the total market capitalisation" and "9 percent of India's total export earnings was contributed by these organisations". Fourthly, government orders for public sector undertakings generally aim at betterment of the society. Finally, public sector undertakings have a direct impact on foreign exchange earnings of the country because their focus is mainly on international trade in goods and services (Public Enterprises Survey, 2016). A recent report highlights that the measures taken by the state for improving performance and commitment of the CPSEs, reflects in their robust growth and development (KPMG, 2012). These above stated reasons only highlight the potential economic significance of the public sector undertakings in determining the Indian business growth.

To address the paucity of research in learning within work groups as well as gaps in the group commitment literature, a model is described and represented that empirically tested the influence of participation in decision making on job satisfaction, group learning and group commitment.

\section{LITERATURE REVIEW}

\section{Participation in Decision Making}

Participation in decision making is defined as sharing the decision making process in order to achieve organisational objectives (Knoop, 1995). Individuals feel a sense of belongingness to the organisation when they are allowed to make suggestions and participate in decision making process. This is due to the fact that employees who make decisions that have their consent in them are more likely to value outcomes (Black \& Gregersen, 1997). Participation in decision making offers employees different levels of influence in making policies ranging from consultative committees to developing good relations with managers. When 
employees participate in decision making, it helps to build their commitment towards the organisation (Kumar \& Giri, 2013).

\section{Job Satisfaction}

Job satisfaction is widely studied in literature. It is a feeling about a job that is determined by the difference between the amount of valued outcome that an individual receives and the outcome he feels he should receive (Halepota $\&$ Shah, 2011). It is an important attribute that is desired by organisations through their employees. This is due to the fact that job satisfaction is an explicit and potential determinant of absenteeism, turnover, in-role job performance, and behaviours within the organisation (Goh, Elliott, \& Quon, 2012). In addition, the primary antecedents of job attitudes are within the ability of the management to influence.

\section{Group Learning}

Learning is a process of change in cognition and behaviour, and it does not necessarily follow that these changes will directly enhance performance (Crossan, Lane, \& White, 1999). Group learning is defined as an outcome that represents a new shared understanding among the members of a work group (Wilson, Goodman, \& Cronin, 2007). Learning is an inherently dynamic process that unfolds over time. If a group develops a new level of shared understanding, then it suggests the presence of cohesiveness within the work group. Learning takes place when members of a work group have shared understanding (Senge, 1990).

\section{Group Commitment}

Group commitment is defined as an individual's identification and sense of cohesiveness with other members of the organisation (Randall \& Cote, 1991). It is one of the less researched concepts in commitment research (Cohen, 2003). Most of the research on group commitment related it to organisational commitment conceptually or empirically. Randall and Cote (1991) suggested that the importance of work-group commitment is its enhancement of social involvement, and this reinforces the social ties the individual develops with the organisation. They explained that on being hired, one's initial reference group gratifies one's needs for guidance and reassurance and exerts a lasting influence over individual attitudes to the organisation. 


\section{THEORETICAL FRAMEWORK}

\section{Participation in Decision Making and Job Satisfaction}

A study conducted in a large manufacturing organisation had concluded that employees having a high desire to participate in decision making are likely to exhibit high levels of job satisfaction (Ornoy, 2010). Similar fact was observed in a large manufacturing firm and a large public utility firm (Schuler, 1983). Thus employees, who view their organisations behaving in their interest experienced greater job satisfaction (Parnell, 2003). Therefore, it is important to understand when and how workplace participation in decision making contributes to gains for both employees and employers. Information flow and decision making are enriched and communications are more open and transparent (Anderson \& McDaniel, 1999). Thus, the review of literature led to develop the following hypothesis:

H1: Participation in decision making will be positively related to job satisfaction.

\section{Job Satisfaction and Group Commitment}

Certain tasks in organisations demand working in teams. Team spirit should develop among individuals in such cases. Team spirit is positively related to job satisfaction levels of employees in a developing country (Halepota \& Shah, 2011). Randall and Cote (1991) studied that group commitment evolves from social ties of individuals and with job satisfaction in an organisation. When the reference team members provide guidance and support to an individual, his social ties would improve. Further, it generally determines satisfaction with group achievements (Maynard, Mathieu, Marsh, \& Ruddy, 2007; Bishop \& Scott, 2000). Hence, group commitment of the employee would also increase. Thus, the following hypothesis was developed:

H2: Job satisfaction will be positively related to group commitment.

\section{Participation in Decision Making and Group Learning}

Participation in decision making creates arenas that facilitate ties among individuals and groups with different goals and experiential backgrounds (Chattopadhyay, Glick, Miller, \& Huber, 1999). Increase in participation in decision making leads to an increased sharing of existing knowledge among employees of a work group relevant to the functioning of the organisation (Huber, 1991). Organisations that support participation in decision making aide group learning (Kuo, 2011). 
Participation in decision making may help employees to work with responsibility. In this way, participation may help them to learn by facilitating interaction between them. This led to proposal of the following hypothesis.

H3: Participation in decision making will be positively related to group learning.

\section{Group Learning and Group Commitment}

Learning mainly developed in the psychological field over a long evolutionary history (Wang \& Ahmed, 2001). Learning occurs with shared understanding and group dynamics of the members in a work group in an organisation (Pantouvakis \& Bouranta, 2013). Learning among group members may develop bonding between them (Limpibunterng \& Johri, 2009). This may help them to identify themselves with their respective work groups. It is also believed that learning within a work group benefits commitment of the members towards the group (Johnson \& Yang, 2010). This led to the formulation of the following hypothesis:

H4: Group learning will be positively related to group commitment.

\section{Participation in Decision Making and Group Commitment}

Research in general supports a link between participation in decision making and commitment (Appelbaum et al., 2013). Employees often regard participation in decision making as a way to believe that their efforts are being recognised (Giri \& Kumar, 2013). Participation in decision making facilitates group performance (Chen, Kirkman, Kanfer, Allen \& Rosen, 2007). When employees have the ability to participate in decision making, they perceive it as an organisational support that may facilitate group commitment (Kukenberger et al., 2015). Thus, the following hypothesis was proposed:

H5: Participation in decision making will be positively related to group commitment.

\section{Job Satisfaction and Group Learning}

Job satisfaction has been widely researched. It is considered necessary for the members of a work group in order to have group learning. It is believed, learning that an employee receives depends on the level of his satisfaction with job (Goh et al., 2012; Alonderiene, 2010; Chiva \& Alegre, 2008). Learning within groups, 
which is boosted by job satisfaction, is known to facilitate organisational and individual goals (Rowden \& Ahmad, 2000). A happy employee often tries to identify with his job and tries to interact and learn from the group members (Wang, 2007). These arguments led to framing of the following hypothesis:

H6: Job satisfaction will be positively related to group learning.

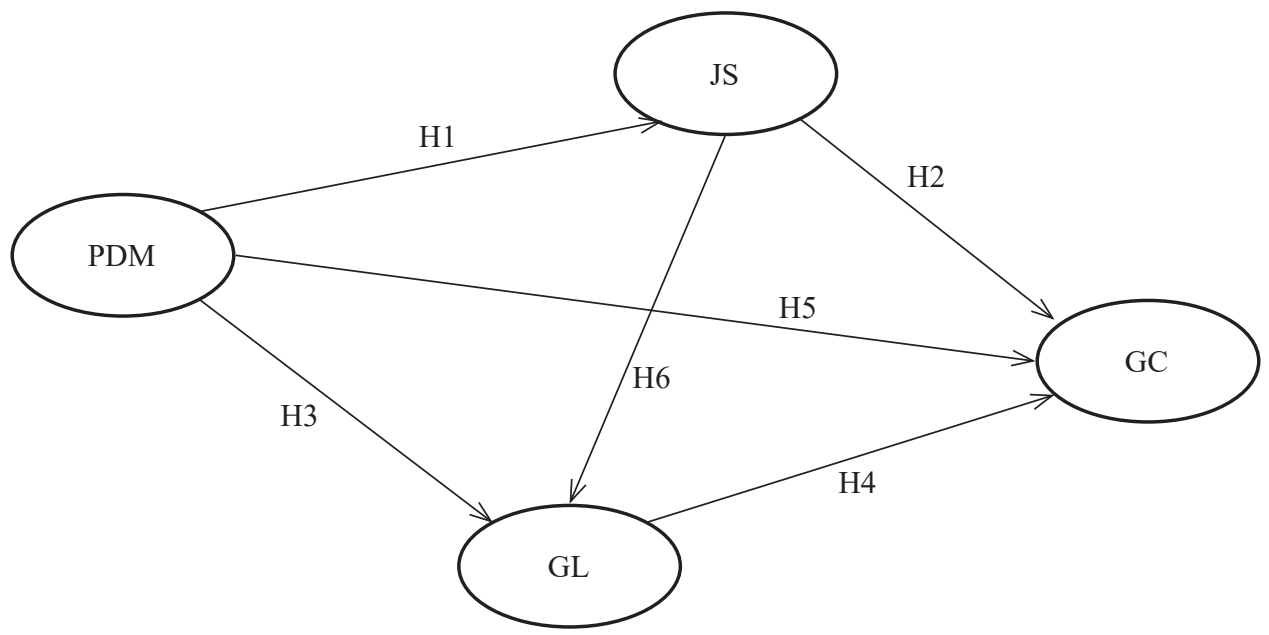

Figure 1. Hypothesised model

Note: $\mathrm{PDM}=$ participation in decision making; $\mathrm{JS}=$ job satisfaction; $\mathrm{GL}=$ group learning; $\mathrm{GC}=$ group commitment; + indicates positive impact

\section{METHODOLOGY}

\section{The Sample}

Convenience sampling technique was adopted to identify organisations. Convenience sampling has been adopted for many studies related to organisational behaviour (Verma \& Duggal, 2015). The sample consists of employees from different departments namely, human resource, finance, electrical, instrumentation, civil, environment, tender and contract, sales, production, chemical, lab, research and development, and several other departments. Participation of employees in this study was voluntary. Respondents were asked not to disclose their identities so that the identities are anonymous. They were requested to respond to all the questions. 
This procedure entails participation from all regions based on convenience, willingness, interest, and availability of respondents to obtain quality responses (Teddlie \& Yu, 2007). The sample includes executives of different departments namely, electrical, mechanical, instrumentation, finance, etc. Participation in the study was voluntary and identities of participants were kept anonymous. Anonymity and confidentiality were preserved in this way leading to more accurate responses. A passive consent approach was adopted. The receipt of a completed questionnaire was left at the discretion of the respondent. The respondents had the liberty of not answering any particular question. However, they were requested to answer leaving out least number of questions.

The target population of the present study consists of employees belonging to managerial cadre. A total data of 397 employees have been collected from different hierarchical levels, that is, junior, middle, and senior levels. The business organisations comprised of public sector undertakings located in various parts of India. These public sector undertakings were selected in such a way that they represented bauxite mining and petroleum products industries. According to IBEF Report (2016), the oil and gas sector is among the core industries in India and plays a major role in influencing decision making for all the other important sections of the economy. In addition, India's economic growth is closely related to energy demand; therefore the need for oil and gas is projected to grow more, thereby making the sector quite conducive for investment (IBEF Report, 2016). Electronics, transportation, packaging, and construction industries from all over the world invest in India for buying bauxite thus leading to exports (Aluminium Industry Report, 2016). We personally visited the organisations for collecting data. Data collected from these diverse organisations helped to obtain high statistical power as well as greater occupational heterogeneity (Langelaan, Bakker, van Doornen, \& Schaufeli, 2006). The sample was drawn during the period from May 2015 to December 2015.

Out of the 550 survey questionnaires distributed, 430 (i.e., 78.19\%) questionnaires were received. After rejecting the incomplete questionnaires, 397 (i.e., 72.19\%) questionnaires were retained for the study. Table 1 shows the different demographic characteristics of the sample.

\section{Measures}

A scale developed by van Veldhoven and Meijman (1994) measuring participation in decision making consisting of eight items was used (e.g., "Can you discuss work problems with your superior?"). All items were measured using a five-point Likert scale ranging from 'always' to 'never'. 
Table 1

Sample characteristics

\begin{tabular}{llc}
\hline Demographics & \multicolumn{1}{c}{ Classification } & Results (\%) \\
\hline Gender & Male & 98 \\
& Female & 2 \\
Age-group & $21-30$ years & 20.2 \\
& $31-40$ years & 33.2 \\
& $41-50$ years & 29.5 \\
Marital status & 51-60 years & 17.1 \\
& Single & 18.4 \\
Qualification & Married & 81.6 \\
& B.E./B.Tech & 39.6 \\
Level of management & M.E./M.Tech & 56.4 \\
& Ph.D. & 4 \\
& Entry & 46.6 \\
Maximum tenure & Middle & 39.3 \\
& Senior & 14.1 \\
& With present employer & 33 years \\
& In total work life of employee & 37 years \\
\hline
\end{tabular}

To assess job satisfaction, a scale developed by Warr, Cook \& Wall's (1979) was used which has a total of 15 items. It has two dimensions: intrinsic job satisfaction consisting of seven items (e.g., satisfaction with freedom to choose your own method of working) and extrinsic job satisfaction consisting of eight items (e.g., satisfaction with fellow workers). All items were measured on a five-point Likert scale ranging from 'I am extremely satisfied' to 'I am extremely dissatisfied'.

A scale developed by Bontis, Crossan, and Hulland (2002) was used to assess group learning. It has a total of 10 items (e.g., "In meetings, we seek to understand everyone's point of view."). All items were measured on a five-point Likert scale ranging from 'strongly agree' to 'strongly disagree'.

Group commitment was assessed using Ellemers, de Gilder, and van den Heuvel's (1998) scale. It consisted of seven items (e.g., "I am prepared to do additional work when this benefits my work team"). All items were measured on a five-point Likert scale ranging from 'strongly agree' to 'strongly disagree'. 


\section{Statistical Tools and Techniques Used for Data Analysis}

The Statistical Package for Social Sciences (SPSS) and WarpPLS were used to analyse the data. The hypothesised structural equation model emerging from the review of literature was subjected to analysis and fit tests. Descriptive statistics, developing the correlation matrix, and calculating Cronbach's alpha values of the various measures used in the study have been analysed using SPSS. Partial least squares (PLS) provides many advantages in terms of measurement scales, sample size, and the complexity of the models to be tested as compared with covariancebased structural equation modeling like Lisrel and AMOS (Chin, 2010). The hypothesised model was tested and the conclusions regarding the model fit and acceptance are reported.

\section{RESULTS}

\section{Outer Model / Measurement Model Validation}

The relationship of observed variables with their respective latent constructs comprises the outer model. Indicator reliability, construct reliability, and construct validity (convergent and discriminant validity) is examined. Convergent validity means all observed variables specified under any particular factor should measure only that factor and not any other factor; whereas, discriminant validity means each factor should be different from other factors measured by a particular set of indicators (Kline, 2015).

All the indicators in Table 2 have factor loadings that are close to or above .50 . The indicators JS1, JS3, JS5, and GL14 had factor loadings of .43, .38, .42, and .47 respectively. Indicator loading is preferred to be greater than .50 (Hair, Black, Babin, Anderson, \& Tatham, 2010). Hence, it was decided to exclude these four indicators from further analysis. In addition, it is evident from Table 3 that all variance inflation factor (VIF) values are less than 5. A rule of thumb rooted in the use of WarpPLS for many structural equation modeling (SEM) analyses in the past, as well as past methodological research, suggests that VIFs of 3.3 or lower avoid issues of multicollinearity and high inter-associations among latent variables (Kock \& Lynn, 2012).

Construct validity is established by composite reliability (CR) values of the construct. Composite reliability is considered to be a superior alternative to Cronbach's alpha (Chin, 2010). CR measures the sum of a latent variable's factor 
Table 2

Outer loadings and cross loadings of indicators

\begin{tabular}{|c|c|c|c|c|}
\hline Variable & PDM & JS & GL & GC \\
\hline PDM1 & .50 & .23 & .21 & .19 \\
\hline PDM2 & .54 & .31 & .35 & .24 \\
\hline PDM3 & .55 & .27 & .31 & .27 \\
\hline PDM4 & .53 & .30 & .34 & .29 \\
\hline PDM5 & .73 & .42 & .38 & .24 \\
\hline PDM6 & .77 & .35 & .33 & .26 \\
\hline PDM7 & .72 & .28 & .27 & .21 \\
\hline PDM8 & .70 & .28 & .29 & .30 \\
\hline JS2 & .39 & .67 & .47 & .38 \\
\hline JS4 & .40 & .58 & .43 & .33 \\
\hline JS6 & .18 & .51 & .33 & .31 \\
\hline JS7 & .26 & .57 & .34 & .28 \\
\hline JS8 & .33 & .69 & .47 & .42 \\
\hline JS9 & .34 & .59 & .37 & .34 \\
\hline JS10 & .31 & .70 & .40 & .38 \\
\hline JS11 & .41 & .72 & .52 & .46 \\
\hline JS12 & .38 & .62 & .38 & .28 \\
\hline JS13 & .25 & .68 & .37 & .38 \\
\hline JS14 & .26 & .73 & .42 & .39 \\
\hline JS15 & .17 & .62 & .39 & .36 \\
\hline GL1 & .31 & .36 & .55 & .35 \\
\hline GL2 & .27 & .42 & .59 & .32 \\
\hline GL3 & .32 & .41 & .58 & .39 \\
\hline GL5 & .25 & .43 & .62 & .27 \\
\hline GL6 & .34 & .31 & .55 & .23 \\
\hline GL7 & .27 & .38 & .65 & .33 \\
\hline GL8 & .30 & .42 & .71 & .37 \\
\hline GL9 & .38 & .46 & .73 & .33 \\
\hline GL10 & .30 & .45 & .72 & .37 \\
\hline GC1 & .19 & .29 & .27 & .55 \\
\hline GC2 & .31 & .41 & .42 & .66 \\
\hline GC3 & .20 & .33 & .29 & .67 \\
\hline $\mathrm{GC} 4$ & .28 & .41 & .37 & .71 \\
\hline GC5 & .28 & .47 & .40 & .75 \\
\hline GC6 & .37 & .49 & .46 & .81 \\
\hline GC7 & .26 & .37 & .36 & .79 \\
\hline
\end{tabular}

Note $: \mathrm{PDM}=$ participation in decision making; $\mathrm{JS}=$ job satisfaction; GL = group learning; $\mathrm{GC}=$ group commitment 
loadings relative to the sum of the factor loadings plus error variance. This value ranges from 0 to 1 . This value should be greater than .60 for the validity of a construct. $\mathrm{CR}$ values above the threshold of .70 indicate strong convergent validity (Hair et al., 2010).

From Table 3, the composite reliabilities of all variables range from .84 to .89 . Moreover, both composite reliability indicators and Cronbach's alpha values of all the variables are above the threshold value of .70. Hence, measurements have strong convergent validity.

Table 3

Results of measurement model and reliability

\begin{tabular}{lcccc}
\hline Variable & Reliability (Cronbach's alpha) & CR & AVE & VIF \\
\hline PDM & .78 & .84 & .41 & 1.44 \\
JS & .87 & .89 & .41 & 2.04 \\
GL & .81 & .86 & .41 & 1.93 \\
GC & .83 & .87 & .50 & 1.60 \\
\hline
\end{tabular}

Note: $\mathrm{CR}=$ composite reliability; $\mathrm{AVE}=$ average variance extracted; VIF $=$ variance inflation factor

As the values for Cronbach's alpha in Table 3 are well above the recommended threshold of .70 , hence the reliability of the measurements is considered valid (Chin, 2010).

Table 4

Results of discriminant validity

\begin{tabular}{lcccc}
\hline Variable & PDM & JS & GL & GC \\
\hline PDM & $.64)$ & .48 & .49 & .39 \\
JS & .48 & $(.64)$ & .64 & .57 \\
GL & .49 & .64 & $(.64)$ & .53 \\
GC & .39 & .57 & .53 & $(.71)$ \\
\hline
\end{tabular}

Notes: All correlations are significant at $p<.001$; the diagonal elements represented in shaded gradient are square roots of AVEs of the respective latent variables

Table 4 presents the correlations among the latent variables with square roots of average variance extracted (AVEs) shown on diagonals. Correlation analysis was employed to examine the relationship among participation in decision making, job satsifaction, group learning, and group commitment. For assessing discriminant validity, bivariate correlation of a construct or variable with other constructs should 
be less than the square root of AVE of the construct (Hair, Hult, Ringle, \& Sarstedt, 2016). This is observed for all variables in Table 4 . Thus, discriminant validity of the variables PDM, JS, GL, and GC is established.

\section{Inner Model / Structural Model Validation}

Proposed hypothetical model was prepared in a recursive manner to avoid problems associated with statistical identification (Hair et al., 2016). Figure 2 shows the results of a structural equation modeling analysis aimed at testing the hypothesised effects among the latent variables. The $\beta$ coefficients for each link are shown near the arrows, and they refer to the standardised regression path coefficients associated with statistically significant effects.

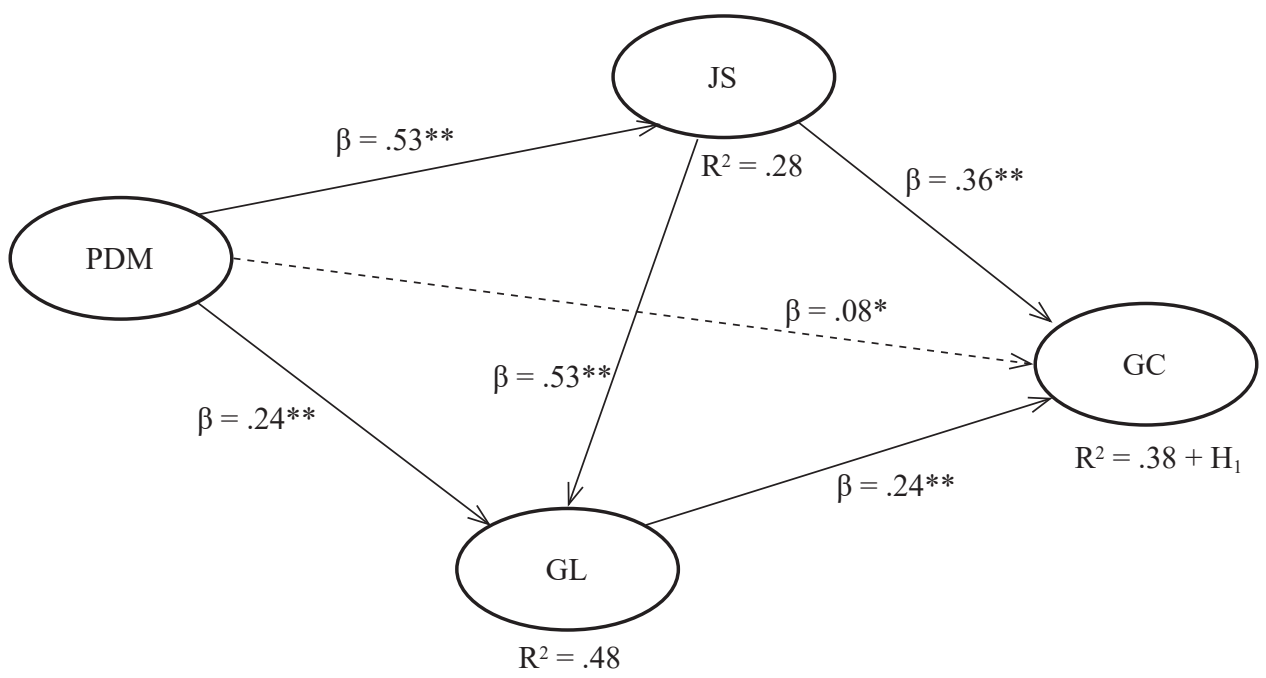

Figure 2. Structural equation model with standardised estimated parameters

Notes: $\beta=$ path coefficients associated with a causal link in the model; ** denotes significant at $p<.01 ; *$ and dotted arrow denote not significant; $\mathrm{R}^{2}=$ variance explained by the model for a particular endogenous latent variable

The strength of each path of the structural equation model and the variance $\left(\mathrm{R}^{2}\right.$ coefficients) of the endogenous constructs should be greater than .1 (Hair et al., 2010). Figure 2 shows that the $\mathrm{R}^{2}$ coefficients of endogenous latent variables are greater than .24 (good amount of variance is explained by the hypothesised variables). $\mathrm{PDM}$ is an exogenous variable, so there exists no $\mathrm{R}^{2}$ value. As evident in Figure 2 and Table 5, all the significant path coefficients are above .24 except for one path which is insignificant. The values of t-statistics are shown in Table 5. 
The value for t-statistic above 2.57 is considered significant above .01 level. All the t-statistics of the significant paths are above 2.57 (Hair et al., 2010). Hence, the structural model is validated.

\section{Model Fit of the Structural Model}

Table 5 shows the model fit indices. All the values of model fit indices like APC, ARS, AARS, AVIF, AFVIF, SPR, RSCR, and NLBCDR fall within the acceptable fit criteria and this indicates a very good model fit.

Table 5

Model fit indices

\begin{tabular}{lcc}
\hline Index & Model results & Model fit criteria \\
\hline Average path coefficient (APC) & $.33, p<.001$ & $p<.001$ \\
Average R-squared (ARS) & $.38, p<.001$ & $p<.001$ \\
Average adjusted R-squared (AARS) & $.37, p<.001$ & $p<.001$ \\
Average block variance inflation factor (AVIF) & 1.72 & $\leq 3.3$ \\
Sympson's paradox ratio (SPR) & 1.00 & $\geq .7$, ideally $=1$ \\
Average full collinearity VIF (AFVIF) & 1.77 & $\leq 3.3$ \\
R-squared contribution ratio (RSCR) & 1.00 & $\geq .9$, ideally $=1$ \\
Statistical suppression ratio (SSR) & 1.00 & $\geq .7$ \\
Nonlinear bivariate causality direction ratio (NLBCDR) & 1.00 & $\geq .7$ \\
\hline
\end{tabular}

\section{RESULTS}

Table 6 shows the hypotheses testing results. The results of the analysis suggest that participation in decision making has a significant and positive relationship with job satisfaction $(\beta=.53, p<.01)$. Hence, hypothesis 1 was accepted. Job satisfaction has significant relationship with group commitment $(\beta=.36, p<.01)$. Thus, hypothesis 2 was accepted. Participation in decision making has significant relationship with group learning $(\beta=.24, p<.01)$. Hence, hypothesis 3 was accepted. Group learning has significant and positive relationship with group commitment $(\beta=.24, p<.01)$. Hence, hypothesis 4 was accepted. Participation in decision making has no significant relationship with group learning $(\beta=.08$, $p=.03$ ) though there was a significant bivariate correlation between participation in decision making and group commitment (.39) evident in Table 4. Hence, hypothesis 5 was refuted. Group learning has a significant and positive relationship with job satisfaction $(\beta=.53, p<.01)$. Hence, hypothesis 6 was accepted. 
Table 6

Summary of hypothesised relationships

\begin{tabular}{clcrc}
\hline Sl. no. of hypothesis & \multicolumn{1}{c}{ Paths } & Path coefficients & t-statistics & Result \\
\hline H1 & PDM $\rightarrow$ JS & $.53^{* *}$ & 12.05 & Accepted \\
H2 & JS $\rightarrow$ GC & $.36^{* *}$ & 8.18 & Accepted \\
H3 & PDM $\rightarrow$ GL & $.24^{* *}$ & 5.45 & Accepted \\
H4 & GL $\rightarrow$ GC & $.24^{* *}$ & 5.45 & Accepted \\
H5 & PDM $\rightarrow$ GC & $.08^{*}$ & 1.82 & Refuted \\
H6 & JS $\rightarrow$ GL & $.53^{* *}$ & 12.05 & Accepted \\
\hline
\end{tabular}

$*$ denotes not significant; $* *$ denotes significant at $p<.01$ level

\section{DISCUSSION}

The positive relationship between participation in decision making and the other constructs like job satisfaction in this study lends credence to previous findings that employees value the opportunity to participate in decision making affecting them (Ornoy, 2010). This might be because of the fact that employees have an increasing desire to take part actively in the internal matters of the organisation. The results suggest that Indian public sector undertakings interested in enhancing employee job satisfaction should consider how effectively the employees participate in decision making which has been supported in previous research.

Job satisfaction is positively related to group learning. This is consistent with previous research findings (Goh et al., 2012). Learning among individuals in an organisation occurs only when there is a supportive work environment. It intends to provide job satisfaction to the employees. When employees are satisfied with their job and co-workers, the social ties of the employees get strengthened. Hence, sharing of existing knowledge within the members or group learning takes place.

Another interesting finding was that participation in decision making has no significant relationship with group commitment. This may be due to the fact that not all employees share the equal amount of participation in decision making in a work group. Employees who are senior may enjoy a slightly higher amount of participation compared to junior employees. Hence, this could lead to demoralisation of the rest of the employees who have lesser right to participate in making decisions. A work group is identified by its group cohesiveness. Unequal distribution of power leads to low group cohesiveness. The performance of a group 
is viewed collectively. Group performance and individual performance are viewed from group perspective and individual perspective respectively. Thus, when the group cohesiveness is hindered, it also hinders the level of group commitment of the employees in a work group.

Group learning was found to have a positive and significant relationship with group commitment. The present finding is in accordance with previous research (Limpibunterng \& Johri, 2009). This is because group learning increases communication among the group members. This helps to build strong social ties. Thus, guidance and support are exhibited by the group members towards each other. Problem-solving skills are enhanced. The feeling of identification of an employee towards his work group increases gradually. Affective commitment towards the work group also increases. In this way, when all the work group employees share a common level of understanding about different job related issues and they are attached with common organisational goals, their commitment towards their work group is facilitated.

Results indicate that participation in decision making is positively and significantly related to group learning as supported by past research (Chattopadhyay et al., 1999). When employees enjoy participation in decision making, they intend to learn, disseminate knowledge within groups, and help in the effective functioning of the organisation. Learning occurs as a result of working over years, or in other words, experience gathered while working on different work aspects over time. Participation means each individual has been assigned some task or responsibility. Participation makes every group member interact with each other to serve the purpose of work. If any member has to clear a work-related query, he will seek help from fellow group members. In this process, group learning takes place.

It is evident that job satisfaction has a significant and positive relationship with group commitment as studied in the past (Bishop \& Scott, 2000). Identification and attachment with the group can be improved by providing supportive work groups and providing recognition within the reference groups for good work. When members of a work group of an individual provide support and guidance in work, the satisfaction obtained by good work will help in observing significant amount of group commitment. Job satisfaction helps members gain a positive feeling about their work. They feel their effort is recognised by management. They feel happy about the fact that their contribution is evident through success of their work group. As this happens, they begin to recognise themselves as important part of their work group. This form of recognising and identifying with the respective work groups leads to building group commitment. 


\section{THEORETICAL IMPLICATIONS}

These findings carry many implications for Indian managers. It is important to identify the different ways to increase commitment and develop measures to improve the same. Unlike in Western cultures, Asians often prefer to work in groups. Collectivist tendencies exist among Asians. There are differences not only in cultures, but also in economic systems. These include the extent to which organisations carry out business and the rules and regulations of governance. South Asian countries, like India, have good business potential as it has high economic growth (Pathardikar, Sahu, \& Jaiswal, 2016). Indians have the essence of 'collectivism' (Hofstede, 1980). Hence, they prefer to work and take decisions collectively. This fact can be leveraged by managers by putting individuals specialising in a particular area together in a work.

Certain tasks are performed individually and also, certain tasks demand collective work in the CPSEs. Individual responses from respondents were obtained for their extent of participation, learning and commitment for this study. Hence, the findings would be relevant to all organisations which function in a similar manner as that of the CPSEs.

Also, experienced employees can work together for good team productivity. Since learning demands cordial relations among employees, this aspect has to be leveraged by the managers to increase group commitment of employees. In addition, this study demonstrates that job satisfaction is positively related to group commitment and group learning. Managers should ensure that highly skilled employees with long tenures work together so that maximum productivity is achieved and the experience passes on to all employees while they share and discuss work.

\section{MANAGERIAL IMPLICATIONS}

The results of this study have certain important implications for managers in Indian workforce. Managers should emphasise on making every employee share certain task or responsibility so that they feel they are contributing towards the success of the organisation. Through participation in decision making, managers can ensure that employees are satisfied and they learn within work groups.

Because participation in decision making is found to play a significant role in job satisfaction, delegating tasks within a work group to meet deadlines is likely to enhance the level of interaction among members. Alonderiene (2010) stated that 
group learning is an important variable found in work groups. Interaction enhances learning within groups. As group learning is found to be responsible for group commitment, managers should ensure that group members have good rapport and cordial relations. Thus, participation in organisations that focuses on enhancing group learning would help to increase group commitment.

With employees experiencing job satisfaction, they will be very happy and content with the kind of work they do. Hence, they will be interested in the type of work they perform. Additionally, they will be able to adapt and learn new changes and techniques in work. Also, group learning has its ability to facilitate group commitment. Hence, managers can focus on making employees satisfied and providing them with certain responsibility so that they learn over the process of working and develop a sense of identification and recognition with the work group.

\section{CONCLUSION}

Participation in decision making is highly desired for managing work groups and individuals working in a work group based environment. Since participation in matters and policies of the organisation makes the employee feel a sense of belongingness towards the organisation, their levels of behavioural outcomes are impacted. Most importantly, effective management of jobs by delegating power throughout all levels of hierarchy would produce positive results to influence group learning and group commitment of employees within a work group.

The managers of public sector undertakings should focus on participation by every potential employee in day-to-day work issues. In this manner, the managers would be able to tap the skills and knowledge of potential employees towards the effective functioning of the organisation. The practice of participative management makes the employee feel empowered to be able to work efficiently and it enhances job satisfaction. Managers should clarify the role and processes of participation and ensure expectations of employees are realistic and equitable. Maintaining a constant dialogue with employees is one way of avoiding misunderstandings and promoting positive outcomes.

\section{LIMITATIONS AND FUTURE SCOPE OF RESEARCH}

Despite its contributions, the present study has certain limitations. This study specifically includes Indian public sector undertakings. Thus, the results of the study should be used carefully while applying to other companies such as 
multinational companies (MNCs). The diverse sample from different MNCs could lead to better understanding of the model. The study considers the cross-sectional data only. This generates a future scope of testing causality with longitudinal data. Whereas, participation is a dynamic process and in order to firmly show relationships, the use of longitudinal study is necessary. Gauging the impact of participative management interventions and team learning interventions on various organisational and behavioural outcomes can be a scope for future researchers. Future research can also be carried with larger sample from different locations across different industries, which would improve the generality of the findings. In addition, research can be extended to other sectors like health care, education, services, and communication so that the findings can have larger implications.

\section{REFERENCES}

Ahmad S. (2013). Paradigms of quality of work life. Journal of Human Values, 19(1), 73-82. https://doi.org/10.1177/0971685812470345

Alonderiene, R. (2010). Enhancing informal learning to improve job satisfaction. Perspective of SMEs managers in Lithuania. Baltic Journal of Management, 5(2), 257-287. https://doi.org/10.1108/17465261011045151

Aluminium Industry Report (2016). Retrieved 2 December 2016 from http://www. aluminiumindustry.org/en/aluminium-industry-india.html.

Anderson, R.A., \& McDaniel, R.R. Jr. (1999). RN participation in organisational decisionmaking and improvements in resident outcomes. Healthcare Management Review, 24(1), 7-16. https://doi.org/10.1097/00004010-199901000-00002

Appelbaum, S.H., Louis, D., Makarenko D., \& Saluja, J. (2013). Participation in decision making: A case study of job satisfaction and commitment (Part I). Industrial and Commercial Training, 45(4), 222-229. https://doi.org/10.1108/ICT-09-2012-0049; https://doi.org/10.1108/00197851311323510 \& https://doi.org/10.1108/ICT-092012-0048

Barney, J. (1991). Firm resources and sustained competitive advantage. Journal of Management, 17(1), 99-120. https://doi.org/10.1177/014920639101700108

Bishop, J.W., \& Scott, K.D. (2000). An examination of organizational and team commitment in a self-directed team environment. Journal of Applied Psychology, 85(3), 439450. https://doi.org/10.1037/0021-9010.85.3.439

Black, J.S., \& Gregersen, H.B. (1997). Participative decision making: An integration of multiple dimensions. Human Relations, 50(7), 859-879. https://doi. org/10.1023/A:1016968625470 \& https://doi.org/10.1177/ 001872679705000705

Bontis, N., Crossan, M., \& Hulland, J. (2002). Managing an organisational learning system by aligning stocks and flows. Journal of Management Studies, 39(4), 437-469. https://doi.org/10.1111/1467-6486.t01-1-00299 
Chattopadhyay, P., Glick, W.H., Miller, C.C., \& Huber, G.P. (1999). Determinants of executive beliefs: Comparing functional conditioning and social influence. Strategic Management Journal, 20(1), 763-789. https://doi.org/10.1002/ (SICI)1097-0266(199908)20:8<763::AID-SMJ46>3.0.CO;2-D

Chen, G., Kirkman, B.L., Kanfer, R., Allen, D., \& Rosen, B. (2007). A multilevel study of leadership, empowerment, and performance in teams. Journal of Applied Psychology, 92(2), 331-346. https://doi.org/10.1037/0021-9010.92.2.331

Chin, W.W. (2010). How to write up and report PLS analyses. In V.E. Vinzi, W.W. Chin, J. Henseler, \& H. Wang (Eds.), Handbook of partial least squares: Concepts, methods and applications in marketing and related fields (pp. 655-690). Berlin: Springer. https://doi.org/10.1007/978-3-540-32827-8_29

Chiva, R., \& Alegre, J. (2008). Emotional intelligence and job satisfaction: The role of organizational learning capability. Personnel Review, 37(6), 680-701. https://doi. org/10.1108/00483480810906900

Cohen, A. (2003). Multiple commitments in the workplace: An integrative approach. Mahwah, NJ: Lawrence Erlbaum Associates.

Crossan, M.M., Lane, H., \& White, R. (1999). An organizational learning framework: From intuition to institution. Academy of Management Review, 24(3), 522-537. https://doi.org/10.5465/AMR.1999.2202135 \& https://doi.org/10.2307/259140

Ellemers, N., de Gilder, D., \& van den Heuvel, H. (1998). Career-oriented versus teamoriented commitment and behaviour at work. Journal of Applied Psychology, 83(5), 717-730. https://doi.org/10.1037/0021-9010.83.5.717

Giri, V.N., \& Kumar, S.P. (2013). Assessing the impact of participation in decision making on organizational citizenship behaviour: The mediating role of oganizational commitment. In D. Chatterjee, M. Dhal, \& S.P. Pati (Eds.), High-tech people, high-tech HR. Are we missing the humane touch? (pp. 41-46). New Delhi: Bloomsbury.

Goh, S.C., Elliott, C., \& Quon, T.K. (2012). The relationship between learning capability and organizational performance. The Learning Organization, 19(2), 92-108. https://doi.org/10.1108/09696471211201461

Gupta, S.J., \& Pannu, H.K. (2013). A comparative study of job satisfaction in public \& private sector. Indian Journal of Arts, 1(1), 3-6.

Hackman, J.R. (1987). The design of work teams. Englewood Cliffs, NJ: Prentice Hall.

Hackman, J.R., \& Morris, C.G. (1975). Group tasks, group interaction processes, and group performance effectiveness: A review and proposed integration. In L. Berkowitz (Ed.), Advances in experimental social psychology (pp. 45-99). New York: Academic Press.

Hair, J.F., Black, W.C., Babin, B.J., Anderson, R.E., \& Tatham, R.L. (2010). Multivariate data analysis (7th ed.). New York: Pearson. https://doi.org/10.1016/j. jmva.2009.12.014

Hair Jr, J.F., Hult, G.T.M., Ringle, C., \& Sarstedt, M. (2016). A primer on partial least squares structural equation modeling (PLS-SEM). Thousand Oaks, CA: Sage Publications. 
Halepota, J.A., \& Shah, N. (2011). An empirical investigation of organisational antecedents on employee job satisfaction in a developing country. Transforming Government: People, Process and Policy, 5(3), 280-294. https://doi. org/10.1108/17506161111155414

Hofstede, G. (1980). Culture's consequences: International differences in work-related values. Thousand Oaks, CA: Sage.

Huber, G.P. (1991). Organizational learning: The contributing processes and the literatures. Organizational Science, 2(1), 88-105. https://doi.org/10.1287/orsc.2.1.88

IBEF (India Brand Equity Foundation) Report (2016). Oil and gas industry in India. Retrieved 2 December 2016 from http://www.ibef.org/industry/oil-gas-india. aspx.

Johnson, R.E., \& Yang, L.Q. (2010). Commitment and motivation at work: The relevance of employee identity and regulatory focus. Academy of Management Review, 35(2), 226-245. https://doi.org/10.5465/AMR.2010.48463332

Kim, S. (2002). Participative management and job satisfaction: Lessons for management leadership. Public Administration Review, 62(2), 231-241. https://doi. org/10.1111/0033-3352.00173

Kline, R.B. (2015). Principles and practice of structural equation modeling. New York: Guilford Publications.

Knoop, R. (1995). Influence of participative decision-making on job satisfaction and organisational commitment of school principals. Psychological Report, 76(2), 379-382. https://doi.org/10.2466/pr0.1995.76.2.379

Kock, N., \& Lynn, G.S. (2012). Lateral collinearity and misleading results in variancebased SEM: An illustration and recommendations. Journal of the Association for Information Systems, 13(1), 546-580.

KPMG (Klynveld Peat Marwick Goerdeler). (2012). Public sector enterprises: Unlocking their true potential. Retrieved 31 January 2016 from http://www.kpmg.com/in/en/ industry/publications/aima-pse.pdf/.

Kukenberger, M.R., Mathieu, J.E., \& Ruddy, T. (2015). A cross-level test of team empowerment and process influences on members' informal learning and commitment. Journal of Management, 41(3), 987-1016. https://doi. org $/ 10.1177 / 0149206312443559$

Kumar, S.P., \& Giri, V.N. (2013). Impact of teachers' participation in decision making on commitment forms in Indian engineering institutions. Pacific Business Review, $5(1), 49-58$.

Kuo, T. (2011). How to improve organizational performance through learning and knowledge? International Journal of Manpower, 32(5), 581-603. https://doi. org/10.1108/01437721111158215

Langelaan, S., Bakker, A.B., van Doornen, L.J., \& Schaufeli, W.B. (2006). Burnout and work engagement: Do individual differences make a difference? Personality and Individual Differences, 40(3), 521-532. https://doi.org/10.1016/j. paid.2005.07.009

Limpibunterng, T., \& Johri, L.M. (2009). Complementary role of organizational learning capability in new service development (NSD) process. The Learning Organization, 16(4), 326-348. https://doi.org/10.1108/09696470910960419 
Louis, K.S., \& Smith, B. (1992). Cultivating teacher engagement: Breaking the iron law of social class. In Newmann, F. (Ed.), Student engagement and achievement in American secondary schools (pp. 119-152). New York: Teachers College Press.

Mathieu, J.E., \& Gilson, L.L. (2012). Critical issues and team effectiveness. In S.J.W. Kozlowski (Ed.), Oxford handbook of organizational psychology (pp. 910-930). New York: Oxford University Press.

Mathieu, J.E., Maynard, M.T., Rapp, T., \& Gilson, L. (2008). Team effectiveness $1997-$ 2007: A review of recent advancements and a glimpse into the future. Journal of Management, 34(3), 410-476. https://doi.org/10.1177/0149206308316061

Maynard, M.T., Mathieu, J.E., Marsh, W.M., \& Ruddy, T. (2007). A multi-level investigation of the influences of employees' resistance to teams and empowerment. Human Performance, 20(2), 147-171. https://doi.org/10.1080/08959280701332885

Ornoy, H. (2010). Correlates of employees' attitudes towards participation in decision making. The IUP Journal of Organisational Behavior, 9(1), 7-15.

Pantouvakis, A., \& Bouranta, N. (2013). The link between organisational learning culture and customer satisfaction: Confirming relationship and exploring moderating effect. The Learning Organisation, 20(1), 48-64. https://doi. org/10.1108/09696471311288528

Parnell, J.A. (2003). Propensity for participative decision-making, job satisfaction, organisational commitment, organisational citizenship behaviour and intentions to leave among Egyptian managers. The Multinational Business Review, 11(1), 45-65. https://doi.org/10.1108/1525383X200300003

Pathardikar, A.D., Sahu, S., \& Jaiswal, N.K. (2016). Assessing organizational ethics and career satisfaction through career commitment. South Asian Journal of Global Business Research, 5(1), 104-124. https://doi.org/10.1108/ SAJGBR-02-2015-0017

Public Enterprises Survey. (2016). Public sector \& government in transformation. Retrieved 27 June 2016 from http://www.ey.com/IN/en/Industries/Government--Public-Sector.

Randall, D.M., \& Cote, J.A. (1991). Interrelationships of work commitment constructs. Work and Occupation, 18(2), 194-211. https://doi.org/10.1177/0730888491018002004

Rowden, R.W., \& Ahmad, S. (2000). The relationship between workplace learning and job satisfaction in small to mid-sized businesses in Malaysia. Human Resource Development International, 3(4), 307-322. https://doi. org/10.1080/13678860050128492

Schuler, R.S. (1983). A role and expectancy perception model of participation in decision-making. Academy of Management Journal, 23(2), 331-340. https://doi. org/10.2307/255435

SCOPE (Standing Conference of Public Enterprises). (2016). PSU at a glance - Highlights. Retrieved 31 March 2017 from http://www.scopeonline.in/PSUs-at-a-glance.php

Senge, P. (1990). The fifth discipline: The art and practice of learning organisations. New York: Doubleday.

Tannenbaum, S.I., Beard, R.L., McNall, L.A., \& Salas, E. (2010). Informal learning and development in organizations. In S.W.J. Kozlowski \& E. Salas (Eds.), Learning, training, and development in organisations (pp. 303-332). New York: Routledge. 
Teddlie, C., \& Yu, F. (2007). Mixed-methods sampling: A typology with examples. Journal of Mixed Methods Research, 1(1), 77-100. https://doi. org/10.1177/2345678906292430

Van Veldhoven, M., \& Meijman, T. (1994). The measurement of psychosocial job demands. Amsterdam: NIA.

Verma, H.V., \& Duggal, E. (2015). Retail service quality in India: Construct exploration and measure development. South Asian Journal of Global Business Research, 4(1), 129-148. https://doi.org/10.1108/SAJGBR-10-2013-0075

Wagner, J.A. III. (1994). Participation's effect on performance and satisfaction: A reconsideration of research evidence. Academy of Management Review, 19(2), 312-330. https://doi.org/10.5465/AMR.1994.9410210753 \& https://doi.org $/ 10.2307 / 258707$

Wang, C.L., \& Ahmed, P.K. (2001, April). Creative quality and value innovation: A platform for competitive success. Proceedings of the 6th Conference of ISO 9000 and TQM Scotland.

Wang, S. (2007). Learning, job satisfaction and commitment: An empirical study of organizations in China. Chinese Management Studies, 1(3), 167-179. https://doi. org/10.1108/17506140710779285

Warr P.B., Cook J.D., \& Wall T.D. (1979). Scales for the measurement of some work attitudes and aspects of psychological well-being. Journal of Occupational Psychology, 52(2), 129-148. https://doi.org/10.1111/j.2044-8325.1979.tb00448.x

Wilson, J.M., Goodman, P.S., \& Cronin, M. (2007). Group learning. Academy of Management Review, 32(4), 1041-1059. https://doi.org/10.5465/AMR.2007. 26585724 
